Full-length article

\title{
Inducible nitric oxide synthase contributes to intermittent hypoxia against ischemia/reperfusion injury ${ }^{1}$
}

Hai-lei DING ${ }^{2}$, Hai-feng ZHU², Jian-wen DONG ${ }^{2}$, Wei-zhong ZHU², Wei-wei YANG ${ }^{3}$, Huang-tian YANG ${ }^{3}$, Zhao-nian $\mathrm{ZHOU}^{2,4}$

${ }^{2}$ Physiological Laboratory of Hypoxia, Shanghai Institutes for Biological Sciences, Chinese Academy of Sciences, Shanghai 200031, China; ${ }^{3}$ Laboratory of Molecular Cardiology, Health Science Center, Shanghai Institutes for Biological Sciences, Chinese Academy of Sciences and Shanghai Second Medical University, Shanghai 200025, China

\section{Key words}

intermittent hypoxia; ischemia/reperfusion; inducible nitric oxide synthase; aminoguanidine; rats

${ }^{1}$ Project supported by the National Natural Science Foundation of China (No 30393130 ) and the Science and Technology Committee of Shanghai Municipality (No 02JC14038).

${ }^{4}$ Correspondence to Prof Zhao-nian ZHOU.

Phn 86-21-5492-0305.

Fax 86-21-5492-0306.

E-mailznzhou@server.shcnc.ac.cn

Received 2004-05-13

Accepted 2004-1 1-03

doi: $10.1111 /$ j.1745-7254.2005.00046.x

\begin{abstract}
Aim: To investigate the role of inducible nitric oxide synthase (iNOS)-derived nitric oxide (NO) in the cardioprotection of intermittent hypoxia (IH) against ischemia/reperfusion (I/R) injury. Methods: Langendorff-perfused isolated rat hearts were used to measure variables of left ventricular function during baseline perfusion, ischemia, and reperfusion period. Nitrate plus nitrite (NOx) content in myocardium was measured using a biochemical method. iNOS mRNA and protein expression in rat left ventricles were detected using reverse transcription polymerase chain reaction (RT-PCR) and Western blot, respectively. Results: Myocardial function recovered better in $\mathrm{IH}$ rat hearts than in normoxic control hearts. The iNOS-selective inhibitor aminoguanidine (AG) $(100 \mu \mathrm{mol} / \mathrm{L})$ significantly inhibited the protective effects of $\mathrm{IH}$, but had no influence on normoxic rat hearts. The baseline content of NOx in IH hearts was higher than that in normoxic hearts. After 30 min ischemia, the NOx level in normoxic hearts increased compared to the corresponding baseline level, whereas there was no significant change in IH hearts. However, the NOx level in IH hearts was still higher than that of normoxic hearts during ischemia and reperfusion period. AG $100 \mu \mathrm{mol} / \mathrm{L}$ significantly diminished the NOx content in IH and normoxic hearts during ischemia and reperfusion period. The baseline levels of iNOS mRNA and protein in IH hearts were higher than those of normoxic hearts. Compared to the corresponding baseline level, iNOS mRNA and protein levels in normoxic rat hearts increased and those in IH rat hearts decreased after reperfusion. The addition of AG $100 \mu \mathrm{mol} / \mathrm{L}$ significantly decreased iNOS mRNA and protein expression in IH rat hearts after $I / R$. Conclusion: IH upregulated the baseline level of iNOS mRNA and protein expression leading to an increase in NO production, which may play an important role in the cardiac protection of IH against I/R injury.
\end{abstract}

\section{Introduction}

Intermittent hypoxia, or periodic exposure to hypoxia interrupted by a return to normoxia or less hypoxic conditions, is encountered more frequently in life than sustained hypoxia ${ }^{[1,2]}$. Many studies have shown that intermittent hypoxia adaptation might have cardioprotective effects similar to those observed in ischemic preconditioning
(IPC) $^{[3-6]}$. To date, several potential factors have been proposed to be involved in the protective mechanisms afforded by $\mathrm{IH}^{[4-10]}$; however, the precise mechanisms in which $\mathrm{IH}$ increases resistance to myocardial ischemia remain far from clear.

Beall et al reported that exhalation of nitric oxide (NO) by chronically hypoxic populations of Tibetans and Bolivian Aymara is unexpectedly increased compared with low-alti- 
tude populations $^{[11]}$. The similar response of these two geographically separate high-altitude populations underlines the importance of NO for life under hypoxic stress. Beall et al speculated that one possible adaptation to maintaining highoutput NO synthesis under hypoxia included increased expression of the synthase enzymes themselves. Nitric oxide synthase (NOS) are a family of three isozymes responsible for the production of NO: the constitutive endothelial (eNOS) and neuronal (nNOS) isozymes and the inducible isozyme. It is known that iNOS is expressed in a wide variety of cell types, including cardiac myocytes. iNOS is usually expressed in response to various physiological and pathophysiological stimuli, such as intense exercise and hypoxia. Recent studies have shown that NO plays an important role in protecting myocardium from I/R injury ${ }^{[12-14]}$. In addition, studies have indicated that the cardioprotective effects of late preconditioning observed after $24 \mathrm{~h}$ resulted from the upregulation of NOS and, more specifically, of iNOS ${ }^{[15,16]}$. Neckar et $a l^{[17]}$ reported that the cardioprotective effects of chronic hypoxia and IPC were not additive, suggesting that the mechanisms of protection conferred by chronic hypoxia and preconditioning may share some common signaling pathways. At present, little is known about the role of iNOSderived $\mathrm{NO}$ in the cardioprotection of $\mathrm{IH}$ and there is no evidence about the changes in iNOS mRNA and protein in IH rat hearts subjected to ischemia and reperfusion. The aim of the present study was to evaluate: (i) the effect of aminoguanidine (AG) on the post-ischemic recovery of left ventricular function in $\mathrm{IH}$ rat hearts, thereby determining the role of iNOS-derived NO in the cardioprotection afforded by IH; and (ii) the effect of IH on iNOS mRNA and protein expression in rat hearts during baseline perfusion, ischemia and reperfusion period.

\section{Materials and methods}

Animal preparation Adult male Sprague-Dawley rats (Clean grade, Shanghai Experimental Animal Center, Chinese Academy of Sciences, Shanghai, China), initially weighing 100-130 g and finally weighing 280-330 g, were exposed to intermittent high-altitude hypoxia of $5000 \mathrm{~m}$ in a hypobaric chamber for $6 \mathrm{~h} /$ day. Barometric pressure $\left(p_{\mathrm{B}}\right)$ was lowered to the level equivalent to an altitude of $5000 \mathrm{~m}$ $\left(p_{\mathrm{B}}=54 \mathrm{kPa} ; p_{2}=11.3 \mathrm{kPa}\right)$. The total number of exposures was 42-day. The temperature in the chamber was maintained at $22-24{ }^{\circ} \mathrm{C}$. The animals were examined the day after the last hypoxic exposure. The control group of animals was kept under normoxic environmental conditions. All animals were maintained with a natural light-dark cycle (12 h Light:

\section{$12 \mathrm{~h}$ Dark).}

Isolated rat heart perfusion The rats were anesthetized with sodium pentobarbital (60 $\mathrm{mg} / \mathrm{kg}$, ip) as previously described $^{[9]}$. Hearts were quickly excised and mounted on a Langendorff apparatus for a retrograde perfusion with KrebsHenseleit solution (K-H buffer solution) at a constant pressure of $80 \mathrm{mmHg}$. K-H buffer solution contains (mmol/L): $\mathrm{NaCl} 118.0, \mathrm{KCl} 4.7, \mathrm{CaCl}_{2} 2.5, \mathrm{MgSO}_{4} 1.2, \mathrm{NaHCO}_{3} 25.0$, $\mathrm{KH}_{2} \mathrm{PO}_{4} 1.2$, glucose 11.0 , and sodium pyruvate 2.0. The medium was continuously gassed with $95 \% \mathrm{O}_{2}$ and $5 \% \mathrm{CO}_{2}$ (pH 7.4) and maintained at $37^{\circ} \mathrm{C}$. A water-filled latex balloon connected to a pressure transducer (Gould P23Db) was introduced into the left ventricle via the mitral valve to record isovolumic left ventricular pressure. The balloon volume was adjusted to achieve a stable left ventricular end-diastolic pressure (LVEDP) of 5-10 $\mathrm{mmHg}$ during the initial equilibration. Heart rate (HR), left ventricular peak systolic pressure (LVPSP), LVEDP, left ventricular developed pressure (LVDP), coronary flow (CF), and the peak rate of pressure developed $\left( \pm \mathrm{d} p / \mathrm{d} t_{\max }\right)$ were monitored using a PowerLab system (AD Instrument Ltd, Castle Hill, Australia). LVDP=LVPSP-LVEDP. Pressure-rate product (PRP) was calculated, PRP $=\mathrm{HR} \times$ LVDP.

Experimental protocol and groups We chose $A G$, an iNOS-specific inhibitor ${ }^{[18]}$, to detect its effect on the cardioprotection of IH. Rats were divided into four groups: (1) corresponding control (CON) group; (2) CON+AG group; (3) IH group; and (4) IH+AG group. In the present study, we used $20 \mathrm{~min}$ baseline perfusion, $30 \mathrm{~min}$ no-flow global ischemia, followed by $30 \mathrm{~min}$ reperfusion protocol. The hearts of rats in the drug group were treated with AG $100 \mu \mathrm{mol} / \mathrm{L}$ for $5 \mathrm{~min}$ before ischemia and maintained during $30 \mathrm{~min}$ ischemia, followed by $30 \mathrm{~min}$ reperfusion with $\mathrm{K}-\mathrm{H}$ buffer solution. To obtain samples for biochemical, RT-PCR, and Western-blot experiments, each group was further divided into three subgroups: (1) baseline perfusion group: $20 \mathrm{~min}$ baseline perfusion; (2) ischemia group: $20 \mathrm{~min}$ baseline perfusion followed by 30 min no-flow global ischemia; and (3) ischemia/ reperfusion group: $20 \mathrm{~min}$ baseline perfusion, $30 \mathrm{~min}$ no-flow global ischemia, followed by $30 \mathrm{~min}$ reperfusion. At the end of baseline perfusion, ischemia, and reperfusion, respectively, the hearts were dissected into left and right ventricles, frozen in liquid nitrogen, and stored at $-80^{\circ} \mathrm{C}$.

Nitrate plus nitrite (NOx) measurement NOx, the stable end product of NO, was assessed as nitrite concentration after conversion of nitrate to nitrite with nitrate reductase and measured using a commercial kit (Nanjing Jiancheng Bioengineering Institute, Nanjing, China). NOx was designated as $\mu \mathrm{mol} / \mathrm{g}$ protein. Its concentration was determined 
at an optical density of $550 \mathrm{~nm}$ in a spectrophotometric method. Protein determination was carried out according to the Bradford method using bovine serum albumin as the standard.

RNA isolation and semi-quantitative determination of iNOS using RT-PCR Total RNA was extracted from frozen ventricular tissue with Trizol reagent and quantified by absorption at $260 \mathrm{~nm}$. Reverse transcription from $0.5 \mu \mathrm{g}$ total RNA was incubated in a $20-\mu \mathrm{L}$ mixture containing $40 \mathrm{U}$ reverse transcriptase, $500 \mu \mathrm{mol} / \mathrm{L}$ of each $\mathrm{dNTP}, 500 \mathrm{ng}$ oligo(dT) and reaction buffer at $42{ }^{\circ} \mathrm{C}$ for $50 \mathrm{~min}$. The sequences of the iNOS primers were 5'-ACTGCTGGTGGTGACAAG-3' (forward) and 5'-CGTTGGAAGTGTA-GCGTT-3' (reverse), allowing the amplification of a 333-bp fragment; the sequences of the M28S primers were 5' AGCAGCCGACTTAGAACTGG-3' (forward)and5'-TAGGGACAGTGGGAATCTCG-3' (reverse), allowing the amplification of a 250-bp fragment. The PCR contained $0.1 \mu \mathrm{mol} / \mathrm{L}$ of each primer, 200 $\mu \mathrm{mol} / \mathrm{L}$ of each dNTP, $2.5 \mathrm{mmol} / \mathrm{L} \mathrm{MgCl}_{2}$ reaction buffer and $1 \mathrm{U}$ Taq DNA polymerase in a final reaction volume of $20 \mu \mathrm{L}$. The reaction mixture was incubated in a thermocycler (Eppendorf Mastercycler gradient, Germany) programmed to predenature at $94{ }^{\circ} \mathrm{C}$ for $5 \mathrm{~min}$, denature at $94{ }^{\circ} \mathrm{C}$ for $40 \mathrm{~s}$, anneal at $60^{\circ} \mathrm{C}$ for $40 \mathrm{~s}$, and extend at $72{ }^{\circ} \mathrm{C}$ for $40 \mathrm{~s}$ for a total of 38 cycles. The last cycle was followed by a final elongation at $72{ }^{\circ} \mathrm{C}$ for $5 \mathrm{~min}$ and cooled to $4{ }^{\circ} \mathrm{C}$. A pilot experiment had shown that this cycle number allowed product detection within the linear phase of amplification.

The amplified products were electrophoresced on a $1.0 \%$ agarose gel stained with ethidium bromide, visualized under ultraviolet light, and scanned using Gel doc 2000 (Bio-Rad, Richmond, CA, USA). The results were expressed as the relative intensity of bands for iNOS PCR product normalized by the intensity of the band for M28S.

Preparation of protein extracts and Western blot analysis of iNOS isozyme The protein extracts were prepared by homogenizing the left ventricles in isotonic sucrose buffer A (mmol/L): Tris-HCl 20.0, sucrose 250.0, $\mathrm{Na}_{3} \mathrm{VO}_{4}$ $0.03, \mathrm{MgCl}_{2}$ 2.0, edetic acid 2.0, egtazic acid 0.5, PMSF 2.0, DTT 1.0, protease inhibitor cocktail $0.02 \%$ (v/v), pH 7.4. The homogenates were centrifuged at $100000 \times g$ for $60 \mathrm{~min}$ at $4{ }^{\circ} \mathrm{C}$ to separate the particulate fraction from the cytosolic fraction. The supernatant containing soluble NOS, designated as cytosol, was used for the Western blot analysis of iNOS.

After boiling for $10 \mathrm{~min}$, equivalent amounts of cytosolic protein $(40 \mu \mathrm{g})$ were separated by $8 \%$ denaturing sodium dodecyl sulfate (SDS)-polyacrylamide gel electrophoresis (PAGE), electroblotted onto a nitrocellulose membrane and immunoreacted with iNOS primary antibody (Santa Cruz Biotech, Santa Cruz, CA, USA) overnight at $4{ }^{\circ} \mathrm{C}$, followed by a $2-\mathrm{h}$ incubation at room temperature with the second antibody (goat anti-rabbit IgG, Sigma Chemical Company, St Louis, MO, USA) conjugated with horseradish peroxidase. The iNOS isozyme was detected using enhanced chemiluminescence (ECL, Amersham Biosciences, UK) as 130-kDa bands. Each iNOS isozyme signal was normalized to the standard signal of the normoxic control heart. The scanned image was imported into Adobe Photoshop software; scanning densitometry was used for quantitative analysis of the data.

Materials and reagents $A G$ was purchased from the Sigma Chemical Company; Trizol isolation reagent was from Invitrogen Life Technologies (San Diego, CA, USA); primers of iNOS and M28S were synthesized by Sangon Bioengineering Company (Shanghai, China); and the reverse transcription system was obtained from Promega (Madison, WI, USA).

Statistical analysis All data are expressed as mean \pm SD. Statistical analysis were carried out using one-way ANOVA or Student's $t$ tests when appropriate. Differences were considered significant at $P<0.05$.

\section{Results}

Effects of AG on recovery of CF and ventricular function after I/R in IH and normoxic rats Our previous study showed that the ratio of whole ventricle weight to body weight of rats in IH groups was not significantly different from normoxic control animals, which meant that intermittent hypoxia in this experimental condition did not result in heart hypertrophy ${ }^{[6,19]}$. The present study demonstrated that CF was slightly but significantly higher in IH hearts during baseline perfusion (Table 1). CF dramatically decreased during reperfusion in all groups, but the improvement of CF during reperfusion was greater in the IH group compared with the normoxic control group. The addition of AG $100 \mu \mathrm{mol} / \mathrm{L}$ did not significantly change either pre-ischemic CF or LVDP, but inhibited pre-ischemic $\pm \mathrm{d} p / \mathrm{d} t_{\max }$ in normoxic and $\mathrm{IH}$ hearts (data not shown). The addition of AG $100 \mu \mathrm{mol} / \mathrm{L}$ inhibited the improvement of CF during reperfusion in the IH group, but had no influence on normoxic hearts.

As shown in Table 1, HR did not change in any group and was not affected by AG $100 \mu \mathrm{mol} / \mathrm{L}$. Baseline values of ventricular function variables did not differ in any group during baseline perfusion, except for $\mathrm{CF}$, but the values of LVPSP, $\pm \mathrm{d} p / \mathrm{d} t_{\max }$, and PRP were greatly decreased, whereas LVEDP significantly increased during reperfusion. During 
Table 1. Hemodynamic parameters in normoxic and intermittent hypoxia hearts at baseline perfusion and after 30 min reperfusion. CON, normoxic control hearts $(n=8), \mathrm{CON}+\mathrm{AG}$, normoxic hearts pretreated with $100 \mu \mathrm{mol} / \mathrm{L}$ aminoguanidine (AG) for 5 min before ischemia and during ischemia $(n=6)$; IH, intermittent hypoxia hearts $(n=8)$, IH+AG, intermittent hypoxia hearts pretreated with $100 \mu$ mol/L AG for 5 min before ischemia and during ischemia $(n=7)$. Mean \pm SD. ${ }^{\mathrm{b}} P<0.05,{ }^{\mathrm{c}} P<0.01$ vs corresponding baseline perfusion. ${ }^{\mathrm{e}} P<0.05,{ }^{\mathrm{f}} P<0.01 v s$ corresponding of $\mathrm{CON}$. ${ }^{\mathrm{h}} P<0.05,{ }^{\mathrm{i}} P<0.01$ vs corresponding of $\mathrm{IH}$.

\begin{tabular}{|c|c|c|c|c|c|}
\hline & & $\mathrm{CON}$ & $\mathrm{CON}+\mathrm{AG}$ & $\mathrm{IH}$ & $\mathrm{IH}+\mathrm{AG}$ \\
\hline \multirow[t]{7}{*}{ Perfusion } & $\mathrm{CF}(\mathrm{mL} / \mathrm{min})$ & $15.1 \pm 0.6$ & $15.6 \pm 1.2$ & $17.3 \pm 1.1^{\mathrm{f}}$ & $17.1 \pm 1.3^{\mathrm{e}}$ \\
\hline & LVPSP (mmHg) & $114.8 \pm 9.3$ & $112.2 \pm 8.6$ & $112.8 \pm 15.3$ & $113.9 \pm 7.9$ \\
\hline & LVEDP $(\mathrm{mmHg})$ & $6.1 \pm 2.2$ & $6.3 \pm 1.2$ & $5.3 \pm 2.0$ & $6.2 \pm 0.9$ \\
\hline & HR (beat/min) & $350 \pm 34$ & $347 \pm 23$ & $354 \pm 37$ & $345 \pm 21$ \\
\hline & $+\mathrm{d} p / \mathrm{d} t_{\max }(\mathrm{mmHg} / \mathrm{s})$ & $2832 \pm 274$ & $2853 \pm 226$ & $2947 \pm 168$ & $2904 \pm 153$ \\
\hline & $-\mathrm{d} p / \mathrm{d} t_{\max }(\mathrm{mmHg} / \mathrm{s})$ & $-2418 \pm 255$ & $-2437 \pm 203$ & $-2452 \pm 352$ & $-2514 \pm 212$ \\
\hline & $10^{-3} \times \mathrm{PRP}(\mathrm{mmHg} / \mathrm{min})$ & $38.4 \pm 3.4$ & $37.6 \pm 4.1$ & $38.6 \pm 5.4$ & $38.2 \pm 4.2$ \\
\hline \multirow[t]{7}{*}{ Reperfusion } & $\mathrm{CF}(\mathrm{mL} / \mathrm{min})$ & $6.3 \pm 1.4^{\mathrm{c}}$ & $6.1 \pm 1.3^{\mathrm{c}}$ & $10.6 \pm 2.0^{\mathrm{cf}}$ & $6.4 \pm 1.2^{\mathrm{ci}}$ \\
\hline & LVPSP (mmHg) & $92.7 \pm 7.4^{\mathrm{b}}$ & $93.6 \pm 7.1^{\mathrm{b}}$ & $93.8 \pm 6.5^{\mathrm{b}}$ & $91.9 \pm 6.9^{\mathrm{b}}$ \\
\hline & LVEDP (mmHg) & $77.2 \pm 6.6^{\mathrm{c}}$ & $78.5 \pm 5.2^{\mathrm{c}}$ & $68.0 \pm 6.7^{\text {ce }}$ & $79.0 \pm 5.8^{\mathrm{ch}}$ \\
\hline & HR (beat/min) & $308 \pm 25$ & $303 \pm 27$ & $313 \pm 26$ & $309 \pm 37$ \\
\hline & $+\mathrm{d} p / \mathrm{d} t_{\max }(\mathrm{mmHg} / \mathrm{s})$ & $484 \pm 32^{c}$ & $448 \pm 43^{\mathrm{c}}$ & $760 \pm 91^{\mathrm{cf}}$ & $397 \pm 52^{\text {ci }}$ \\
\hline & $-\mathrm{d} p / \mathrm{d} t_{\max }(\mathrm{mmHg} / \mathrm{s})$ & $-437 \pm 39^{c}$ & $-374 \pm 47^{\mathrm{c}}$ & $-662 \pm 68^{\mathrm{cf}}$ & $-336 \pm 47^{\mathrm{ci}}$ \\
\hline & $10^{-3} \times \mathrm{PRP}(\mathrm{mmHg} / \mathrm{min})$ & $5.0 \pm 0.4^{\mathrm{c}}$ & $4.7 \pm 0.5^{\mathrm{c}}$ & $8.1 \pm 0.7^{\mathrm{cf}}$ & $3.9 \pm 0.8^{\mathrm{ci}}$ \\
\hline
\end{tabular}

$\mathrm{CF}$, coronary flow; LVPSP, left ventricular peak systolic pressure; LVEDP, left ventricular end-diastolic pressure; HR, heart rate; $\pm \mathrm{d} p / \mathrm{d} t_{\text {max }}$, peak rate of pressure developed; PRP, pressure-rate product.

reperfusion, values of $\pm \mathrm{d} p / \mathrm{d} t_{\max }, L V E D P$, and PRP in the IH group were superior to the normoxic group, suggesting that left ventricular functional recovery was modestly facilitated by IH adaptation. AG significantly inhibited the recovery of IH hearts, whereas it had no effect on normoxic hearts during reperfusion (Figure 1).

Effects of AG on the nitrate/nitrite content of IH and normoxic rat hearts The biochemical experiment demonstrated that the baseline content of NOx in IH hearts was $30.4 \%$ higher than that in normoxic hearts $(P<0.01)$. After 30 min ischemia, the NOx level in normoxic heart tissue increased from $0.608 \pm 0.060$ to $0.747 \pm 0.062 \mu \mathrm{mol} / \mathrm{g}$ protein, whereas in IH heart tissue there was no significant change $(P>0.05$, $0.793 \pm 0.075$ vs $0.837 \pm 0.054 \mu \mathrm{mol} / \mathrm{g}$ protein). The addition of AG $100 \mu \mathrm{mol} / \mathrm{L}$ significantly diminished the content of NOx in IH hearts from $0.837 \pm 0.054$ to $0.606 \pm 0.070 \mu \mathrm{mol} / \mathrm{g}$ protein and from $0.747 \pm 0.062$ to $0.541 \pm 0.062 \mu \mathrm{mol} / \mathrm{g}$ protein in normoxic hearts during the ischemia period. AG also significantly decreased the content of NOx in IH hearts from $0.742 \pm 0.062$ to $0.535 \pm 0.072 \mu \mathrm{mol} / \mathrm{g}$ protein and from $0.617 \pm$ 0.072 to $0.519 \pm 0.059 \mu \mathrm{mol} / \mathrm{g}$ protein in normoxic hearts during the reperfusion period (Figure 2).

Effects of AG on iNOS mRNA expression in IH and normoxic rat hearts The expression of iNOS mRNA is shown in Figure 3A,3B. The baseline level of iNOS mRNA in
IH hearts was higher than that in normoxic hearts by $50.2 \%$ $(P<0.01)$. After reperfusion, iNOS mRNA level in normoxic hearts increased from $0.470 \pm 0.051$ to $0.590 \pm 0.092(P<0.05)$; however, the iNOS mRNA level in IH hearts decreased from $0.706 \pm 0.061$ to $0.549 \pm 0.066$ after reperfusion $(P<0.05)$. The addition of $100 \mu \mathrm{mol} / \mathrm{L}$ AG significantly diminished iNOS mRNA level in normoxic and IH hearts after reperfusion; however, the reduced extent of IH hearts was higher than that of normoxic hearts $(P<0.01)$.

Effects of AG on iNOS protein expression in IH and normoxic rat hearts The expression of iNOS protein is demonstrated in Figure 4A, 4B. In accordance with the changes at mRNA level, the baseline level of iNOS protein in IH hearts was $33.8 \%$ higher than that of normoxic hearts $(P<0.05)$. After reperfusion, iNOS protein level in the normoxic hearts increased by $18.4 \%$ (from $100 \% \pm 0.0 \%$ to $118.4 \% \pm 8.4 \%, P<0.05)$; however, iNOS protein level in IH hearts decreased by $31.9 \%$ (from $133.8 \% \pm 16.6 \%$ to $91.1 \% \pm$ $7.0 \%, P<0.01)$. After reperfusion, the level of iNOS protein between normoxic and IH hearts was significantly different $(P<0.05)$. The addition of $100 \mu \mathrm{mol} / \mathrm{LAG}$ significantly decreased iNOS protein level in IH hearts; however, AG had no influence on iNOS protein expression in normoxic hearts after reperfusion. Ischemia significantly decreased iNOS protein expression in the different groups $(P<0.05)$. 

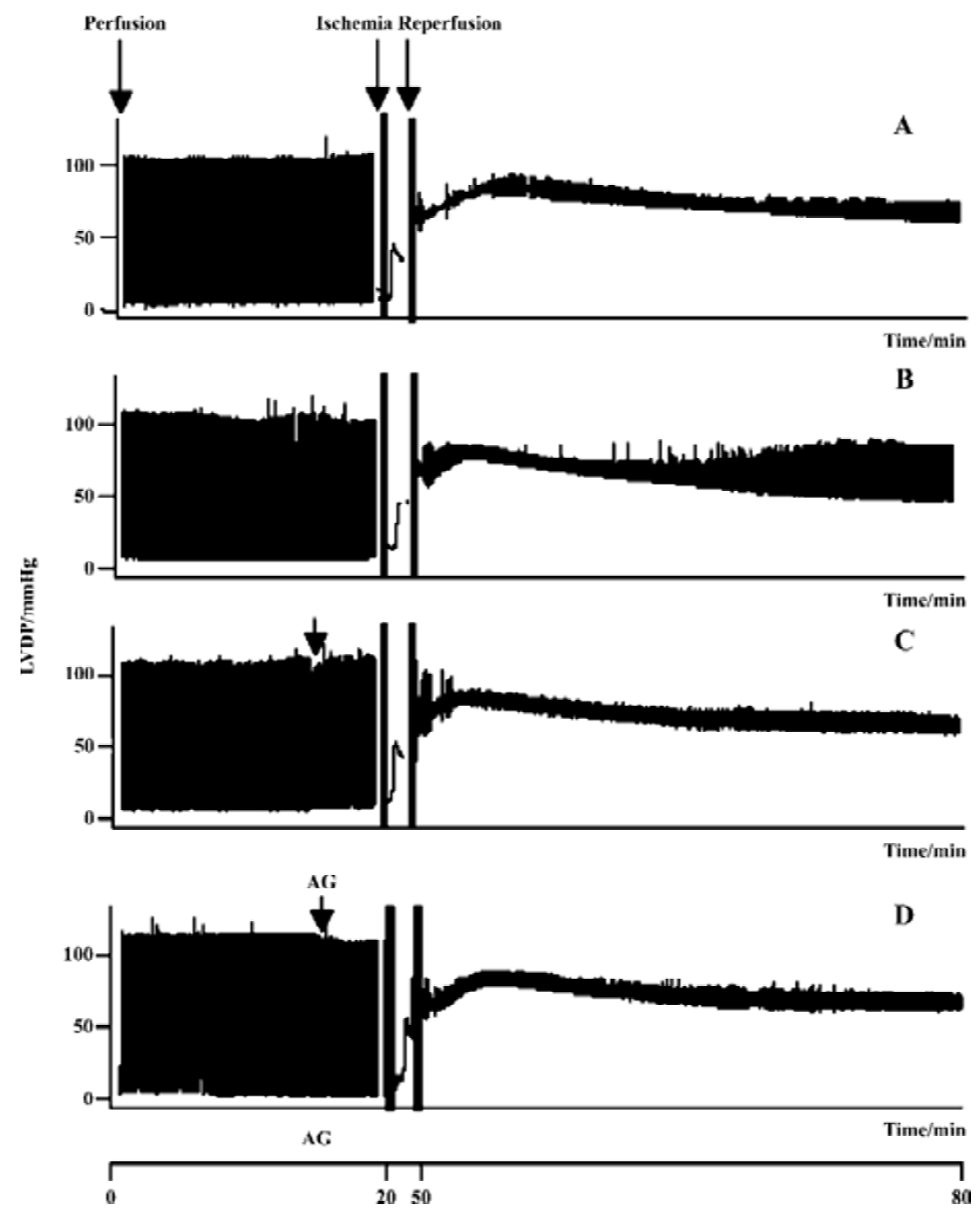

Figure 1. Original recording of left ventricular developed pressure in isolated Langendorff-perfused rat hearts in different groups during $20 \mathrm{~min}$ baseline perfusion, $30 \mathrm{~min}$ ischemia, and $30 \mathrm{~min}$ reperfusion. The arrow indicates the times of the different treatments. (A) normoxic control heart; (B) intermittent hypoxia (IH) heart; (C) normoxic heart pretreated with aminoguanidine (AG) $100 \mu$ mol/L for 5 min before ischemia and during ischemia; and (D) IH heart pretreated with AG $100 \mu \mathrm{mol} / \mathrm{L}$ for $5 \mathrm{~min}$ before ischemia and during ischemia.

\section{Discussion}

The present study showed that IH increased the tolerance of hearts to I/R injury, determined by improved recovery of post-ischemic ventricular function. This protective effect was abolished by AG, suggesting that iNOS-derived NO may participate in the cardioprotection of IH. Our results also showed that the baseline level and the recovery of $\mathrm{CF}$ after ischemia were higher in IH hearts compared with normoxic hearts. Zhong et al's study revealed that capillary densities were increased in IH hearts, which contributed to better functional recovery when isolated rat hearts were sub- jected to an I/R injury ${ }^{[6]}$. The recovery of post-ischemic CF in IH hearts was abolished by AG, suggesting that iNOSderived NO may be involved in the improvement of CF by IH.

The level of NOS expression relates directly to the quantity of NOx production. To examine the effect of IH on iNOS expression, we investigated NOx content, iNOS mRNA, and protein expression in normoxic and $\mathrm{IH}$ rat hearts during baseline perfusion. Providing important additional insights into IH against I/R injury, we also examined NOx content, iNOS mRNA and protein expression in IH and normoxic rat 


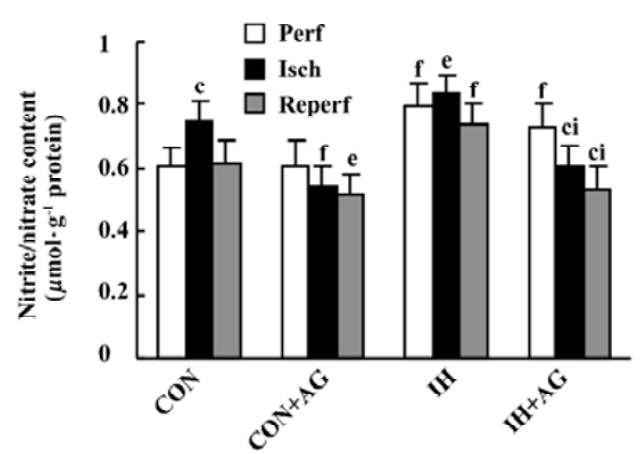

Figure 2. Nitrite/nitrate level in normoxic and intermittent hypoxia (IH) rat hearts treated with or without $100 \mu \mathrm{mol} / \mathrm{L}$ aminoguanidine (AG). $n=6$ rats. Mean \pm SD. Perf, perfusion; Isch, ischemia; Reperf, reperfusion. ${ }^{\mathrm{c}} P<0.01 v s$ corresponding Perf. ${ }^{\mathrm{e}} P<0.05,{ }^{\mathrm{f}} P<$ $0.01 v s$ corresponding control $(\mathrm{CON})$. ${ }^{\mathrm{i}} P<0.01 \mathrm{vs}$ corresponding $\mathrm{IH}$.
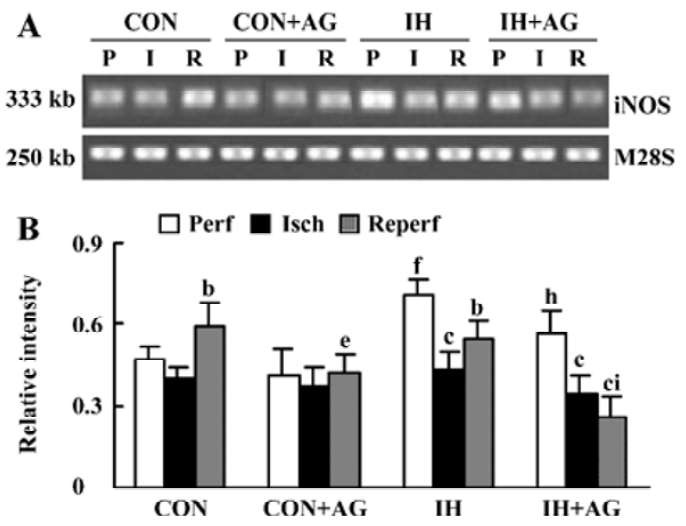

Figure 3. The mRNA expression of inducible nitric oxide synthase (iNOS) isozyme in normoxic and intermittent hypoxia $(\mathrm{IH})$ rat hearts treated with or without $100 \mu \mathrm{mol} / \mathrm{L}$ aminoguanidine (AG). (A) Top panel shows mRNA levels of iNOS; bottom panel shows M28S mRNA, which was used as an internal control. (B) Relative intensity of iNOS mRNA was determined relative to M28S mRNA. $n=5$ rats. Mean \pm SD. $\mathrm{P}$ and Perf, perfusion; I and Isch, ischemia; $\mathrm{R}$ and Reperf, reperfusion. ${ }^{\mathrm{b}} P<0.05,{ }^{\mathrm{c}} P<0.01 v s$ corresponding Perf. ${ }^{\mathrm{e}} P<0.05,{ }^{\mathrm{f}} P<0.01$ vs corresponding control $(\mathrm{CON}) .{ }^{\mathrm{i}} P<0.01$ vs corresponding $\mathrm{IH}$.

hearts subjected to ischemia/reperfusion. This may help us to understand why IH could improve the post-ischemic recovery of left ventricular function. Our results showed that iNOS mRNA and protein were unregulated and that NOx content increased after IH adaptation in rat hearts. Palmer et al showed that hypoxia induced iNOS expression in cardiac myocytes and vascular endothelial cells ${ }^{[20,21]}$. RouetBenzineb et al also indicated that after 15 days of hypoxia there was a two-fold increase in iNOS protein abundance in rat left ventricles ${ }^{[22]}$. However, Baker et al demonstrated that
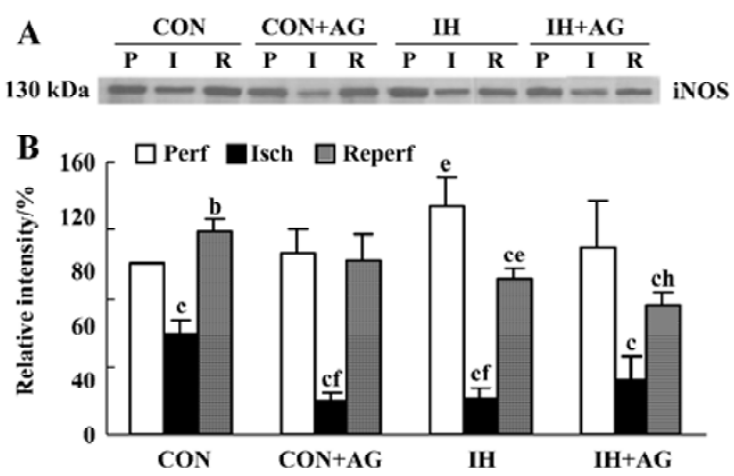

Figure 4. The protein expression of inducible nitric oxide synthase (iNOS) isozyme in normoxic and intermittent hypoxia (IH) rat hearts treated with or without $100 \mu \mathrm{mol} / \mathrm{L}$ aminoguanidine (AG). The immunoreactive band of iNOS was detected using Western blot. (A) The band shows protein expression of iNOS during various periods in different groups; (B) Relative intensity of iNOS protein level was determined relative to a selected standard signal of the normoxic control heart. $\mathrm{P}$ and Perf, perfusion; I and Isch, ischemia; R and Reperf, reperfusion. $n=5$ rats. Mean \pm SD. ${ }^{\mathrm{b}} P<0.05,{ }^{\mathrm{c}} P<0.01$ vs corresponding Perf. ${ }^{\mathrm{e}} P<0.05,{ }^{\mathrm{f}} P<0.01$ vs corresponding control (CON). ${ }^{\mathrm{h}} P<0.05$ vs corresponding $\mathrm{IH}$.

increased tolerance to ischemia in rabbit hearts adapted to chronic hypoxia was associated with increased expression of eNOS isozymes, which led to an increase in myocardial nitrite/nitrate content and cGMP level ${ }^{[23]}$. The signaling functions of NO begin with its binding to protein receptors, such as guanylyl cyclase, which generates cGMP. In the present study, the elevated expression of myocardial iNOS in IH hearts compared to control hearts was also consistent with Zhong et al's report ${ }^{[6]}$, which showed that the myocardial cGMP level in IH rats increased compared to normoxia control rats. Baker et al suggested that a small increase in NO levels appears to be cardioprotective, whereas a large increase in NO production may be detrimental, resulting in vasodilation, decreased blood pressure and, perhaps, vascular leakage ${ }^{[23]}$. Importantly, in our study the magnitude of iNOS upregulation caused by IH was mild. This quantitative induction of iNOS may be critical in explaining the protective effects of iNOS following IH adaptation. The discrepancies between Baker et al's study and ours lie in the age of the animals (adult $v s$ neonatal), the species (rabbit vs rat), the experimentalmodel, and the training duration and/or intensity.

In the present study, iNOS-derived NO was assessed by measuring the AG-inhibitable nitrite/nitrate content in IH and normoxia rat hearts. The addition of $100 \mu \mathrm{mol} / \mathrm{L}$ AG significantly decreased NOx content, iNOS mRNA and protein levels in IH hearts after reperfusion and abolished the protective effect of IH; AG also decreased NOx content and 
iNOS mRNA expression in normoxic hearts; however, the inhibitory extent was lower in normoxic hearts compared with IH hearts. This result suggests that iNOS is tonically higher in IH hearts compared with normoxic hearts and that iNOS may play an important role in the cardioprotection of IH.

Studies examining the role of NO in modulating ischemia/ reperfusion injury are complicated. There are conflicting reports about the changes in NO content during ischemia/ reperfusion period. A number of studies have demonstrated that NO content increased in hearts subjected to ischemia ${ }^{[24,25]}$. Studies have also shown that short-term ischemia leads to an increase in iNOS activity and expression; however, iNOS activity and expression decreased with prolonged ischemia. This may be related to a deficiency in essential co-factors for protein synthesis and stability (eg, haem, FAD, FMN, calmodulin). In addition to NO production by specific NOS, Zweier et al also demonstrated that NO could be generated in tissues by either direct disproportionation or reduction of nitrite to NO under the acidic and highly reduced conditions that occur in disease states, such as ischemia ${ }^{[26]}$. Thus, we considered that the basal level of nitrite and nitrate was a better index of nitric oxide production from the aerobically perfused heart.

In addition, we found that iNOS mRNA and protein level in normoxic hearts increased after reperfusion; however, iNOS mRNA and protein level decreased in IH hearts. The results from Zingarelli et al's study differed from our result in that iNOS mRNA in wild-type mice was significantly increased after $30 \mathrm{~min}$ reperfusion compared to the basal level ${ }^{[27]}$. In the present study, the level of iNOS protein in normoxic hearts was higher than the level in IH hearts after I/R. It is known that induction of high-output iNOS usually occurs in an oxidative environment, and thus high levels of NO have the opportunity to react with superoxide anion $\left(\mathrm{O}_{2}^{-}\right)$leading to peroxynitrite $\left(\mathrm{ONOO}^{-}\right)$formation and cell toxicity ${ }^{[28]}$. The generation of $\mathrm{ONOO}^{-}$can account for the toxicity of $\mathrm{NO}$ in biological systems. Yasmin et al and Wang and Zweier's studies indicated that generation of $\mathrm{ONOO}^{-}$at reperfusion contributed to the $\mathrm{I} / \mathrm{R}$ injury in isolated rat hearts ${ }^{[29,30]}$. In general, $\mathrm{O}_{2}^{-}$formation increases during the early period of reperfusion and reacts with $\mathrm{NO}$ to form $\mathrm{ONOO}^{-}$, which results in amino acid nitration and cellular injury ${ }^{[30]}$. Our previous study suggested that an increase in antioxidant capacity might play an important role in the effect of $\mathrm{IH}$ reducing $\mathrm{I} / \mathrm{R}$ injury ${ }^{[5]}$. Based on the above investigations, we propose that during reperfusion, normoxic hearts may be predisposed to produce more $\mathrm{O}_{2}^{-}$and $\mathrm{ONOO}^{-}$than $\mathrm{IH}$ hearts, and thus produce more potent toxicity than $\mathrm{IH}$ hearts. Our results also suggest that during reperfusion after sustained ischemia,
NO may have bidirectional effects on myocardium because of the coexistence of $\mathrm{NO}$ and $\mathrm{O}_{2}^{-}$. AG significantly diminished NOx content, iNOS mRNA and protein level in IH hearts after reperfusion and led to the inhibitory effect of $A G$ on the recovery of left ventricular function of $\mathrm{IH}$ rat hearts. As far as we know, NO is considered to play a pivotal role in numerous physiological and pathophysiological processes, with effects arising from both a lack and a surfeit of this chemically reactive molecule. This seemingly paradoxical behavior may be explained by the amount of NO generated, temporal-spatial intracellular compartmentalization of $\mathrm{NO}$, and the intracellular redox environment.

The mechanisms leading to upregulation of iNOS after $\mathrm{IH}$ adaptation and the mechanism whereby iNOS-derived NO plays a role in the protection of IH have not been clarified and need to be further investigated. Mechanisms by which hypoxia induces gene expression include transcriptional and posttranscriptional regulation. The molecular mechanisms of hypoxia adaptations are centered on the activation of hypoxia-inducible factor 1 (HIF-1). During hypoxia, however, HIF- $1 \alpha$ is stabilized, leading to accumulation of the active HIF- $1 \alpha$, HIF- $1 \beta$ heterodimer, which binds to specific recognition elements within promoter/enhancer regions of many target genes, the induction of which generates this cytoprotective process. The set of genes induced in this manner include $\operatorname{NOS}^{[20,21]}$, which drives cytoprotective events mediated by NO. At the same time, complex mechanisms may exist and interplay in the regulation of iNOS expression in the heart.

NO is an important endogenous regulatory molecule involved in a variety of biological functions. For example, it maintains coronary vasodilator tone, inhibits platelet aggregation and the adhesion of neutrophils to vascular endothelium $^{[31]}$. It can also regulate myocardial contractile function. Studies have suggested that NO could also regulate oxygen demand and the delivery of oxygen ${ }^{[32]}$. Therefore, moderate increases in NO during intermittent hypoxia might be involved in the regulation of the above effects.

We concluded that IH upregulated the baseline level of iNOS mRNA and protein expression leading to an increase in NO production, which may play an important role in the cardiac protection of IH against I/R injury.

\section{References}

1 Powell FL, Garcia N. Physiological effects of intermittent hypoxia. High Altitude Med Biol 2000; 1: 125-36.

2 Prabhakar NR. Physiological and genomic consequences of intermittent hypoxia: invited review: oxygen sensing during intermittent hypoxia: cellular and molecular mechanisms. J Appl 
Physiol 2001; 90: 1986-94.

3 Meerson FZ, Ustinova EE, Orlova EH. Prevention and elimination of heart arrhythmias by adaptation to intermittent high altitude hypoxia. Clin Cardiol 1987; 10: 783-9.

4 Asemu G, Papousek F, Ostadal B, Kolar F. Adaptation to high altitude hypoxia protects the rat heart against ischemia-induced arrhythmias. Involvement of mitochondrial $\mathrm{K}_{\mathrm{ATP}}$ channel. J Mol Cell Cardiol 1999; 31: 1821-31.

5 Zhang Y, Zhong N, Zhu HF, Zhou ZN. Antiarrhythmic and antioxidative effects of intermittent hypoxia exposure on rat myocardium. Acta Physiol Sin 2000; 52: 89-92.

6 Zhong N, Zhang Y, Zhu HF, Wang JC, Fang QZ, Zhou ZN. Myocardial capillary angiogenesis and coronary flow in ischemia tolerance rat by adaptation to intermittent high altitude hypoxia. Acta Pharmacol Sin 2002; 23: 305-10.

7 Zhong N, Zhang Y, Fang QZ, Zhou ZN. Intermittent hypoxia exposure-induced heat-shock protein 70 expression increases resistance of rat heart to ischemic injury. Acta Pharmacol Sin 2000; 21: 467-72.

8 Neckar J, Szarszoi O, Koten L, Papousek F, Ost'adal B, Grover GJ, et $a l$. Effects of mitochondrial $\mathrm{K}_{\mathrm{ATP}}$ modulators on cardioprotection induced by chronic high altitude hypoxia in rats. Cardiovasc Res 2002; 55: 567-75.

9 Zhu HF, Dong JW, Zhu WZ, Ding HL, Zhou ZN. ATP-dependent potassium channels involved in the cardiac protection induced by intermittent hypoxia against ischemia/reperfusion injury. Life Sci 2003; 73: $1275-87$.

10 Dong JW, Zhu HF, Zhu WZ, Ding HL, Ma TM, Zhou ZN. Intermittent hypoxia attenuates ischemia/reperfusion induced apoptosis in cardiac myocytes via regulating Bcl-2/Bax expression. Cell Res 2003; 13: 385-91.

11 Beall CM, Laskowski D, Strohl KP, Soria R, Villena M, Vargas E, et al. Pulmonary nitric oxide in mountain dwellers. Nature 2001; 414: 411-2.

12 Jones SP, Girod WG, Palazzo AJ, Granger DN, Grisham MB, Jourd'Heuil D, et al. Myocardial ischemia-reperfusion injury is exacerbated in absence of endothelial cell nitric oxide synthase. Am J Physiol 1999; 276: H1567-73.

13 Weiland U, Haendeler J, Ihling C, Albus U, Scholz W, Ruetten H, et al. Inhibition of endogenous nitric oxide synthase potentiates ischemia-reperfusion-induced myocardial apoptosis via a caspase- 3 dependent pathway. Cardiovasc Res 2000; 45: 671-8.

14 Brunner F, Maier R, Andrew P, Wolkart G, Zechner R, Mayer B. Attenuation of myocardial ischemia/reperfusion injury in mice with myocyte-specific overexpression of endothelial nitric oxide synthase. Cardiovasc Res 2003; 57: 55-62.

15 Guo Y, Jones WK, Xuan YT, Tang XL, Bao W, Wu WJ, et al. The late phase of ischemic preconditioning is abrogated by targeted disruption of the inducible NO synthase gene. Proc Natl Acad Sci USA 1999; 96: 11507-12.

16 Bolli R. Cardioprotective function of inducible nitric oxide synthase and role of nitric oxide in myocardial ischemia and preconditioning: an overview of a decade of research. J Mol Cell Cardiol 2001; 33: 1897-918.

17 Neckar J, Papousek F, Novakova O, Ost'adal B, Kolar F. Cardioprotective effects of chronic hypoxia and ischaemic preconditioning are not additive. Basic Res Cardiol 2002; 97: 161-7.

18 Misko TP, Moore WM, Kasten TP, Nickols GA, Corbett JA, Tilton RG, et al. Selective inhibition of the inducible nitric oxide synthase by aminoguanidine. Eur J Pharmacol 1993; 233: 119-25.

19 Zhang Y, Zhong N, Zhou ZN. Effects of intermittent hypoxia on action potential and contraction on non-ischemic and ischemic rat papillary muscle. Life Sci 2000; 67: 2465-71.

20 Palmer LA, Semenza GL, Stoler MH, Johns RA. Hypoxia induces type II NOS gene expression in pulmonary artery endothelial cells via HIF-1. Am J Physiol 1998; 274: L212-19.

21 Jung F, Palmer LA, Zhou N, Johns RA. Hypoxic regulation of inducible nitric oxide synthase via hypoxia inducible factor-1 in cardiac myocytes. Circ Res 2000; 86: 319-25.

22 Rouet-Benzineb P, Eddahibi S, Raffestin B, Laplace M, Depond S, Adnot $\mathrm{S}$, et al. Induction of cardiac nitric oxide synthase 2 in rats exposed to chronic hypoxia. J Mol Cell Cardiol 1999; 31: 1697-708.

23 Baker JE, Holman P, Kalyanaraman B, Griffith OW, Pritchard KA Jr. Adaptation to chronic hypoxia confers tolerance to subsequent myocardial ischemia by increased nitric oxide production. Ann N Y Acad Sci 1999; 874: 236-53.

24 Zweier JL, Wang PH, Kuppusamy P. Direct measurement of nitric oxide generation in the ischemic heart using electron paramagnetic resonance spectroscopy. J Biol Chem 1995; 270: 304-7.

25 Node K, Kitakaze M, Kosaka H, Komamura K, Minamino T, Inoue $\mathrm{M}$, et al. Increased release of NO during ischemia reduces myocardial contractility and improves metabolic dysfunction. Circulation 1996; 93: 356-64.

26 Zweier JL, Samouilov A, Kuppusamy P. Non-enzymatic nitric oxide synthesis in biological systems. Biochim Biophys Acta 1999; 1411: 250-62.

27 Zingarelli B, Hake PW, Yang Z, O'Connor M, Denenberg A, Wong HR. Absence of inducible nitric oxide synthase modulates early reperfusion-induced NF-kappaB and AP-1 activation and enhances myocardial damage. FASEB J 2002; 16: 327-42.

28 Xie Q, Nathan C. The high-output nitric oxide pathway: role and regulation. J Leukoc Biol 1994; 56: 576-82.

29 Yasmin W, Strynadka KD, Schulz R. Generation of peroxynitrite contributes to ischemia-reperfusion injury in isolated rat hearts. Cardiovasc Res 1997; 33: 422-32.

30 Wang P, Zweier JL. Measurement of nitric oxide and peroxynitrite generation in the postischemic heart. Evidence for peroxynitrite-mediated reperfusion injury. J Biol Chem 1996; 271: 29223-30.

31 Kelly RA, Balligand JL, Smith TW. Nitric oxide and cardiac function. Circ Res 1996; 79: 363-80.

32 Brown GC. Nitric oxide and mitochondrial respiration. Biochim Biophys Acta 1999; 1411: 351-69. 